\title{
REPRESENTAÇÕES SOBRE A POLÍTICA ENTRE LIDERANÇAS POPULARES: limites e potencialidades de uma ferramenta conceitual
}

\author{
Irlys Alencar F. Barreira*
}

\begin{abstract}
Resumo: Aidéia de pensar as representações em seu caráter dinâmico, referenciadas em experiências de vida e modos de atuação política inspirou as principais idéias formuladas no artigo. Com base em enquete realizada entre moradores da periferia de Fortaleza, capital do Estado do Ceará, aliada à técnica de experiência etnográfica, são verificadas as representações como exemplo de categorias nativas, inseridas em um contexto de significados culturais. A investigação atentou para as potencialidades e limites das representações enquanto ferramenta conceitual, verificando como os informantes pensavam as questões da política e da moral associadas aos temas da justiça e das desigualdades sociais.
\end{abstract}

Palavras-chave: representações; política; moral; lideranças.

Uma pesquisa que se efetiva no campo das representações põe em pauta questões metodológicas de grande complexidade referentes, em primeiro plano, à dificuldade de encontrar significados densos e substantivos em um conjunto de discursos construídos de forma dispersa ou, muitas vezes, percebidos como "incoerentes". Em se tratando de representações que se processam no campo da política, a tendência a cristalizar opiniões permanentemente expostas a mudanças e sempre influenciadas por conjunturas específicas revela-se mais fortemente.

A demanda pelo reforço de valores morais, em momentos de circulação de escândalos políticos difundidos nos meios de

\footnotetext{
* Professora Titular do Departamento de Ciências Sociais da Universidade Federal do Ceará. E-mail: ialencar21@uol.com.br
} Artigo recebido em 7 ago. 2009 e aprovado em 23 out. 2009. 
comunicação demassa, oua emergência deideais deruptura provocada pela pressão de instituições autoritárias, indicam a necessidade de pensar o caráter relativo e dinâmico das representações. Isso significa não tomá-las como o estatuto de uma "visão de mundo" cristalizada, mas como expressão relativa e circunstancial de percepções historicamente construídas por diferentes agrupamentos sociais.

Tampouco as representações constituem opiniões voláteis, separadas de práticas sociais cotidianas e direcionamentos sobre modos de vida. As reflexões de Jodelet (1989), amparadas nos postulados durkheimianos, reafirmam o caráter social e a capacidade que têm as representações de nomear e definir comportamentos da vida cotidiana, atuando como espécie de mapa cultural cognitivo. A investigadora que se tornou uma espécie de porta-voz do tema considera que o conteúdo das representações é constituído de elementos informativos, cognitivos, ideológicos, crenças, valores e atitudes envolvidos em uma totalidade significante, um "saber que diz algo sobre a realidade", inseparável da ação e capaz de suscitar formas criativas de investigação científica (Jodelet, 1989, p. 36).

O propósito das reflexões aqui presentes é menos um posicionamento sobre as correntes teóricas ${ }^{1}$ que embasam o conceito de representações e mais a verificação de seu valor como ferramenta operacional de pesquisa. É no espaço de um olhar dialógico com os achados da investigação que dilemas sociológicos clássicos podem ceder lugar à reflexão sobre os cuidados no emprego do conceito e as exigências feitas ao pesquisador no sentido de relativizar opiniões ou pontos de vista que as representações abrigam em seu interior.

As principais idéias formuladas neste artigo inspiram-se na compreensão do lado dinâmico das representações sociais associadas a experiências de vida e modos de percepção sobre a política. Com base em enquete realizada entre moradores da periferia urbana de Fortaleza, capital do Estado do Ceará, aliada à técnica da experiência 
etnográfica, o artigo se propõe a analisar as representações de lideranças populares, verificando o uso de categorias nativas sobre a política, a moral e as desigualdades sociais típicas de um espaço de sociabilidade.

Em se tratando de uma pesquisa realizada no início do século XXI, o objetivo das reflexões não consiste na revelação de significados contemporâneos da política, mesmo que muitas das formulações discursivas dos sujeitos investigados estejam, ainda hoje, fortemente presentes. Originalmente a pesquisa voltou-se para entender as percepções sobre a política e a moral entre moradores de bairros populares, apontando questões interessantes para o aprofundamento do tratamento analítico das representações, pouco abordado naquele momento. ${ }^{2}$ Este novo eixo constitui um dos elementos importantes de reflexão, indicando limites e potencialidades de uma ferramenta conceitual, levando em conta a necessidade de flexibilizar e circunstanciar as representações.

O processo histórico de construção das crenças, baseado na experiência cotidiana de grupos sociais, permitiu pensar as representações como expressões discursivas móveis e flexíveis, ao mesmo tempo em que amparadas na vigência das posições sociais de seus portadores.

Algumas informações iniciais sobre o processo de investigação são relevantes para situar o leitor no contexto relativo da obtenção dos dados.

\section{Breve relato de uma investigação}

A pesquisa foi feita com base em observação de reuniões, comportamentos cotidianos e registro de discursos provenientes de moradores de bairros populares, situados na região metropolitana de Fortaleza. Um questionário de teor mais objetivo, contendo 
questões fechadas e abertas, pretendeu sistematizar as informações, acrescentando-se aos registros de observação de reuniões e de outros rituais presentes no cotidiano dos bairros.

O questionário foi aplicado a 60 representantes de entidades associativas de moradores, sendo 27 homens e 33 mulheres, situados, em sua maioria, na faixa etária entre 31 e 50 anos. Oriundos na maior parte do interior do Estado, os entrevistados possuiam graus diversificados de escolaridade, com maior incidência situada no primeiro grau incompleto. As categorias profissionais mais frequentes referiam-se às atividades de prestação de serviços, professor primário e comerciante, incluindo também profissões tipicamente femininas como costureira, doméstica e dona de casa.

A investigação, na busca de recortar uma espécie de ethos normativo ou matriz simbólica, teve como meta analisar representações de líderes populares, moradores de bairros da periferia oeste de Fortaleza, sobre os temas da política e da moral, associados às noções de desigualdade e injustiça social. Considerando-se esse pano de fundo, algumas perguntas gerais guiaram a investigação: Como os indivíduos formulavam percepções sobre a sua condição social? Como avaliavam comportamentos baseados em critérios morais e qual a imagem que possuíam da política institucional?

O universo dos entrevistados abrangeu, preferencialmente, os presidentes de entidades associativas, incluindo também antigas lideranças que atuavam, de forma pioneira, nas atividades do bairro. A título de exemplo, 40\% dos entrevistados declaravam ter estreado sua participação política através de atuação na associação de moradores, destacando também a importância de outros veículos de iniciação como grupos ligados à igreja, militantes partidários e contato direto com outras lideranças de bairro, incluindo familiares.

A investigação que subsidiou as reflexões aqui presentes ocorreu em diferentes períodos, comportando objetivos distintos. 
Um dos temas propostos referiu-se à análise de "candidaturas populares", verificando o modo como representantes de bairro concebiam a política e, a partir dessa base cognitiva, encontravam estratégias de participação no cenário eleitoral, ou em outros espaços institucionais. Deu continuidade a essa investigação, a pesquisa desenvolvida com apoio da bolsa de produtividade do CNPq, mais centrada nas representações sobre a política e suas interfaces com princípios normativos e hierarquias sociais.

A tentativa de computar sentidos sobre a política, em um plano não restrito ao cenário eleitoral, encaminhou-se para a percepção de hierarquias sociais e valores. A ampliação da observação sobre a esfera restrita da política permitiu incorporar representações vigentes em outros campos de atividade da vida social, enriquecendo as informações obtidas.

Relativizando a suposição de que o discurso de líderes sintetizava e explicitava as representações do conjunto de moradores, preferi colocar esse pretenso suposto como ponto de reflexão, indagando sobre os processos de construção de percepções no contexto desse público específico. Tentava, com essa perspectiva, ultrapassar os cânones de uma pesquisa de opinião, já criticados por Patrick Champagne (1998), referindo-se ao caráter arbitrário e préconstruído de perguntas com capacidade de influir nas respostas. Ao lado desse pressuposto, algumas questões de ordem teórica se impuseram ao longo da investigação. Entre elas, as possibilidades de articulação entre dimensões culturais e políticas, inseparáveis da temática das representações.

\section{As representações e suas interfaces com a "cultura política"}

Os princípios normativos e os valores que cerceiam o mundo da política constituem um sujeito analítico relevante, considerando- 
se as perspectivas teóricas de autores clássicos (Weber, Marx e Durkheim), renovadas por meio de pesquisas recentes. Nestas destaca-se o esforço de compreender as crenças e interpretações daqueles que "fazem a política" e os que dela participam em graus diferenciados. As pesquisas brasileiras que trataram do tema das "representações sobre a política" se debruçaram inicialmente sobre a importância de valores culturais que influenciaram a continuidade ou a ruptura da ordem autoritária (cf. Moisés, 1992; Dagnino, 1994). De modo geral, as concepções vigentes nesse momento insistiam sobre a capacidade das instituições mudarem internamente, pactuando com potencialidades emergentes de modernização.

Os pressupostos designados como "teoria da transição" orientaram-se para a compreensão de caminhos ou vias que permitiriam a passagem da ordem autoritária para a democrática. A atenção voltada para a incorporação de valores democráticos nas práticas cotidianas foi também analisada por autores que sublinhavam a importância das relações sociais e da chamada cultura política no desenrolar do processo democrático (cf. Avritzer, 1995; Costa, 1997).

Uma outra abordagem mais recente sobre as interfaces entre a cultura e a política, considerando o universo das representações, buscou priorizar uma etnografia de eventos, situações e dramas capazes de registrar percepções expressivas da vida social. É a partir desse ponto de vista que este artigo se propõe, de forma mais sistemática, a observar contextos específicos a partir dos quais emergem significados socioculturais da política que podem ser designados como representações. Trata-se de uma abordagem teórica que inclui o estudo de rituais e discursos que se expressam, muitas vezes, por meio de categorias nativas, incorporando concepções sobre a política em conexão com outras esferas da atividade social. ${ }^{3}$

As proximidades entre os campos do conhecimento designados como "política" e "cultura" atravessam caminhos já 
sedimentados sobre a interpretação das representações que regem as escolhas partidárias e incidem sobre os grupos de poder destacandose, mais recentemente, a presença dos meios de comunicação. A análise das pautas, dos textos e imagens que influenciam os comportamentos políticos estão atualmente presentes em pesquisas que gradativamente encaminham-se para entender as motivações eleitorais, o uso do marketing político e demais fenômenos envolvidos por essa percepção da política em um plano abrangente. A presença mais recente de valores culturais no âmbito das análises políticas é, portanto, fruto de mudanças operadas no âmbito de teorias e pesquisas distintas.

No domínio da Antropologia, o conceito de "cultura política" tem sido objeto de crítica, tendo em vista a reivindicação dos valores e diversidades culturais a serem vistos em um universo mais difuso de significados, não relacionados exclusivamente a um campo de atividades. Nesses termos, um aglomerado de opiniões, proveniente de códigos culturais diversos e contraditórios, não possui um sentido unívoco quando transferido para o eixo das atividades políticas. ${ }^{4}$

Um dos exemplos que comprovam a lógica complexa das representações se refere à distância entre determinadas práticas sindicais e escolhas eleitorais. A pesquisa de Moacir Palmeira (1996) sobre trabalhadores sindicais do Maranhão apontou a aparente contradição entre uma prática tida como engajada e combativa de sindicalistas, ao lado de escolhas eleitorais voltadas para o reforço de políticos tradicionais. A interpretação inicial de "incoerência" que essas práticas pareciam supor informava, na verdade, a presença de duas lógicas. Uma concernente às escolhas eleitorais e outra baseada na prática sindical. Os discursos dos trabalhadores justificavam a separação dessas dimensões, apontando a complexidade das representações e a dificuldade de pensá-las de forma estática, ou expressiva de uma "consciência política atrasada". 
Nas investigações sobre as práticas de sociabilidade dos movimentos sociais pude também observar a vigência de lógicas diferenciadas para pensar a "política do bairro" e a prática das instituições de representação democrática, concebida como "a outra política". Nesse caso, "política" era um vocábulo com muitos significados, operando como categoria nativa na definição de práticas sociais diversas.

Esses exemplos apontam a necessidade de se pensar acerca de significados culturais densos que se superpõem às manifestações discursivas mais evidentes, exigindo um trabalho mais complexo com o tema das representações.

A intercessão entre categorias nativas, significados culturais e representações sociais deu subsídios à análise dos dados obtidos na pesquisa, destacando a fecundidade e o limite do conceito. Seguindo essa diretriz, o objetivo perseguido durante a pesquisa com presidentes de associações de bairro foi o de inserir nos discursos uma unidade de referência circunscrita a uma experiência mais ampla, um contexto. Tratava-se de pensar os discursos como sintomas ou indicações de "visões de mundo" fundamentadas em experiências diversificadas.

As representações foram então analisadas como suporte de experiências diversificadas e variáveis, inseridas em um contexto específico de sociabilidade dos moradores. Supunha-se, portanto, que os discursos eram constituídos por certas caracteristicas gerais sinalizadoras da presença da politica nos segmentos sociais pesquisados, presença que indicava também o caráter plural das representações, mediadas por um conjunto de códigos sociais.

\section{Contexto de produção das representações sobre a política}

Embora as concepções elaboradas sobre a política não sejam atributos restritos a algum segmento social, tornou-se quase lugar 
comum considerar que moradores de zonas mais longínquas da cidade de Fortaleza, nomeados de "moradores da periferia", organizados ou não em associações, eram informantes privilegiados. Foi justo nesse espaço onde se observou a intervenção de políticas sociais, as práticas de associativismo transformadas em espécies de escola de socialização política e o lugar no qual se consolidavam clientelas eleitorais. Não por acaso, identifica-se essa zona urbana como um contexto onde a "política", com todas as suas adjetivações, realiza investimentos, sendo avaliada de forma positiva ou negativa.

Em momentos eleitorais, nos quais os ritos de apresentação de candidatos supõem um percurso itinerante, a "periferia" emerge como o lugar onde "está o povo" beneficiado ou desprotegido, mas sempre à espera de que a política, ou melhor, os políticos "cheguem lá". Inúmeros comícios foram realizados nesses locais, além de visitas e reuniões que visavam aproximações entre a "política" e a "população". 5

A ampliação das organizações de bairro, no período que antecedeu e sucedeu imediatamente a chamada transição democrática, viabilizou também um olhar otimista, permeado pela ideia de que tais organizações traziam sementes de renovação democrática. Posteriormente, a intervenção de políticas sociais, nomeadas de "participativas" exigiram a intermediação de associações para o repasse de bens de consumo coletivos, corroborando para o aumento significativo de entidades de bairro e a solidificação de cargos de representação ocupados por "presidentes".

O saldo dessas múltiplas situações de comunicação com a política foi a presença de inúmeras associações de moradores com participantes na função de presidentes e interlocutores que passaram a falar "em nome do bairro" e de seus habitantes. Foi dentre esse grupo de presidentes de associações que se buscou a análise sobre as representações construídas a respeito da política e suas interfaces com os temas da moral e das desigualdades sociais. 


\section{Versões sobre a política}

As representações ou concepções sobre a política e as hierarquias sociais são normalmente objeto de um princípio de diferenciação que separa grupos ("os políticos e a "população), hierarquiza relações (os que têm poder e os que não têm) e cristaliza territórios ("os moradores da periferia" e "moradores de outros bairros").

Quando se observa, por exemplo, o modo como segmentos sociais residentes em bairros periféricos e conhecidos como “moradores pobres" classificam a política, os políticos e a si próprios verifica-se que os princípios de inclusão e exclusão evocam, além de variáveis como renda e consumo, nomeadas como objetivas, as maneiras como tais grupos sociais "incorporam" o "seu lugar". Um lugar muitas vezes descrito em escala valorativa e compensatória, confirmando as observações de Caldeira (1984) sobre a pobreza do bairro de São Miguel Paulista - zona Leste de São Paulo - percebida como carente de bens materiais, porém virtuosa em seus valores morais.

Indagados sobre a principal razão para o ingresso nas atividades do bairro, 53\% dos entrevistados mencionaram "gostar de ajudar as pessoas", seguidos de 48,3\% que afirmaram a "vontade de mudar a situação do bairro". As conexões entre as atividades realizadas no espaço da moradia e no mundo privado eram bastante fortes, evidenciadas no apoio de parentes aos trabalhos desenvolvidos no bairro $(83,3 \%)$.

É importante ressaltar que as ações de organização e mobilização coletivas, bem como as estratégias de melhoria de serviços e equipamentos no bairro apareciam também como extensão das atividades do mundo privado. O bairro era assim uma espécie de ampliação da casa, pois através das melhorias urbanas conquistadas como iluminação, posto de saúde e escola era possível obter maior conforto familiar. 
Dentre os trabalhos realizados pelos entrevistados no bairro, destacavam-se, em primeira ordem, serviços básicos de infra-estrutura (25\%), seguidos de educação $(21,7 \%)$ e habitação e construção (18.4\%). Os informantes tinham uma percepção das atividades do bairro como parte de seu trabalho cotidiano, não inteiramente alheio ao universo da política, mas, por vezes, distanciados de formas efetivas de participação no cenário insitucional. As opiniões expostas a seguir apontam o modo como percebiam a "outra política" em contraponto às ações desenvolvidas no bairro, normalmente concebidas como estando articuladas a uma identidade de interesses.

\section{A outra política}

As versões sobre os significados da política separavam o ser e o dever-ser. Com base nesse pressuposto, a resposta sobre a questão das motivações que levavam à ação política no bairro eram justificadas, tendo em vista a suposição de devoção aos "compromissos coletivos", concebidos em oposição aos "interesses e vantagens pessoais". Estes apareciam exemplificados em objetivos econômicos, conectados a atitudes negativas, que viam a política como uma atividade capaz de induzir as pessoas a "tirarem proveitos pessoais e ganharem às custas dos pobres". A política de caráter "comunitário", em oposição, valorizava os interesses coletivos, evocando ideais de "transformação social" e supondo, consequentemente, que poderia haver um outro modo intervir na gestão pública capaz de produzir melhoria nos bairros. A maneira diferenciada de fazer política dependia das qualidades pessoais de representantes oficiais

Dentre as características que um bom político deveria ter para o desempenho eficaz de suas atividades, os valores morais -relativos àhonestidade, dignidade, sinceridade-tiveram supremacia $(58,3 \%)$ sobre os demais, seguidos de atributos relativos a valores 
de identificação com os moradores do bairro. Assim, ser "popular", "nordestino", "ser da cidade", ter a "bandeira do povo", ou possuir nas mãos a "cicatriz de uma enxada", constituíam pressupostos importantes para o desempenho de um profissional da política. A busca de uma identificação com o político surgia como requisito básico para sua credibilidade e reconhecimento. A afirmação de candidaturas populares consideradas autênticas e diferentes das demais modulava uma espécie de compensação da decepção com "a outra política". ${ }^{6}$

As características importantes atribuídas a um "líder comunitário" - expressão designada para identificar o representante do bairro e dirigente de associações de moradores -, coincidiam com aquelas apontadas como imprescindíveis para o exercício de um mandato político. Nesse sentido, a honestidade aparecia com $68,3 \%$ de preferência, seguida de compromisso, sinceridade e responsabilidade. Estes seriam elementos comprovadores da eficácia de valores morais, capazes de se contraporem à visão negativa atribuída à política e aos seus representantes. A dimensão de representatividade no bairro funcionava, inclusive, como uma espécie de reserva moral, tendo em vista a propagação de um "ethos comunitário" que guiava o discurso de grande parte dos representantes de entidades do bairro.

No cômputo dessa visão, a pergunta "você se considera um líder?" destacava alguns atributos relacionados a uma resposta não mais pessoal, mas referida a qualidades específicas da condição de liderança: responsabilidade, capacidade, simplicidade, dedicação. $\mathrm{Na}$ maioria das falas dos entrevistados, a intitulação de líder era percebida como classificação externa, sendo considerada a autoatribuição um sintoma de vaidade pessoal:

Eu prefiro dizer que eu sou comunitário. Comunitário é minha ética. 
Líder é uma palavra muito forte. Me considero apenas reconhecida pelo meu trabalho.

Não fica bem dizer que sou líder mas as pessoas acham que sim, eu quero ser, mas não sei se sou (Lurdes, liderança comunitária do bairro Henrique Jorge).

Quanto à comparação sobre os processos eleitorais "na comunidade" e as eleições em outras instâncias da política oficial, $80 \%$ das respostas afirmavam que os princípios deveriam ser os mesmos. O conjunto das respostas destacava, no entanto, opiniões que separavam a "política do bairro" e a política oficial: "na comunidade, as pessoas votam em quem conhecem, na política votam sem conhecer", "os políticos só vem aqui em dia de eleição. "O representante do bairro está aqui todos os dias".

Observa-se, através dessas afirmações, que a política e os políticos são percebidos como estando em esferas longínquas e não acessíveis ao conjunto dos cidadãos comuns. Em tais circunstâncias, a política institucional é concebida como estando separada do cotidiano dos moradores, mesmo que os bairros sejam permeados de formas internas de organização e associativismo não separadas de partidos políticos e programas governamentais. Uma das frases expressivas dessa visão antagônica da política efetivada no interior do bairro e nas instâncias legalizadas do poder era a seguinte: "existe outra política onde as pessoas se iludem com os agrados. $\mathrm{Na}$ comunidade não pode haver isso não".

\section{A negatividade do poder}

Tão logo era perguntado se o poder corrompia, as resposta eram claras, denotando a atribuição negativa da política como um dos supostos importantes da representação de moradores. Nesse quesito, $82 \%$ das respostas foram postivas, sendo justificadas por meio das seguintes opiniões provenientes de vários líderes, presidentes e expresidentes de associação de moradores: 
Tem muitas pessoas que humilham os outros quando têm o poder.

Poder lembra dinheiro e política. O poder devia ser do povo.

O poder lembra injustiça e destruição. Poder é egoísmo e falta de sensibilidade.

A pessoa quando está em baixo é humilde, quando está no poder esquece a humildade.

Uma liderança comunitária não pode pensar que tem poder.

Quem tem poder são os ricos.

Quem tem poder quer comprar as pessoas. A começar pela justiça porque os advogados são corruptos.

Quando as pessoas assumem o cargo de chefe mudam completamente.

As representações sobre o poder que distanciam o político de seus eleitores pontuam parte significativa da visão de segmentos da sociedade brasileira. Nessa mesma direção, a pesquisa de Magalhães (1998) realizada em bairros populares da cidade de Porto Alegre revela características semelhantes baseadas na relação entre política e poder.

Políticos são mentirosos, prometem e não cumprem. Bom é um candidato saído das camadas baixas, trabalhador... mas lá em São Borja, eu me lembro de um amigo nosso, conhecido, pessoa boníssima, que se candidatou. Nós todos ajudamos ele, mas quando se sentiu no poder, ficou vaidoso, se afastou do pessoal... (Informante Lilia apud Magalhães, 1998, p. 46).

As versões críticas acerca do poder, difundidas entre os informantes da pesquisa realizada em Fortaleza, observam esse atributo como espécie de instância capaz de desvirtuar princípios. "Uma minoria com boas intenções é corrompida pela maioria". Existe, nesse sentido, a percepção do poder como sendo um espaço maculado da política. Política e poder aparecem como situações articuladas, sendo este último considerado um dos atributos vulneráveis dos representantes, em posição contrária à do líder comunitário, que é visto como alguém que "não tem poder". O poder 
é também representado como uma força propulsora negativa, capaz de romper as regras de contrato entre políticos e eleitores: "Quando as autoridades pegam o poder que nós damos a eles, eles se acham poderosos, mandam em tudo e nos rebaixam".

As concepções sobre o poder e a política constituem terreno fértil para se verificar clivagens sociais e o modo como determinados segmentos elaboram sentimentos de exclusão e inclusão, transformando-os em modos de atuação, formas de pertencimento e identificação. Observa-se, pelo conjunto das opiniões emitidas durante a pesquisa, que o poder é visto como elemento externo, sobretudo quando referido à chamada política oficial, percebida como distante e, às vezes, inalcançável.

Não deixa de ser sintomática a necessidade de pensar a organização comunitária como sendo a expressão de espaço opositor, não submetido a clivagens partidárias, nas quais as diferenças e hierarquias são assumidas como parte constitutiva do jogo político. Talvez, também por esse motivo, se possa entender que eventuais conflitos de poder, no "interior da comunidade", possam ser vistos como desvirtuamento do que deveria se apresentar como unitário e indiferenciado. Nesse caso, os conflitos operariam como espécie de divisor de águas, aproximando-se de características aplicadas à "outra política".

As referências ao poder são, portanto, reveladoras de que ele é um dos pólos nos quais se referenciam as clivagens sociais. Tudo se passa como se a sociedade pudesse ser dividida entre poderosos e não poderosos, sendo o poder um dos espaços potenciais de corrupção.

A discussão remonta também à existência de regras normativas que estruturam diferentes práticas sociais, criando zonas de interseção da política com a moral, referenciadas em percepções sobre a desigualdade e a justiça social. 


\section{Moral e justiça: as zonas de interseção da política}

Como pensar os móveis que articulam a moral, a justiça, a política segundo a visão dos moradores? As discussões sobre questões ligadas à moral e à justiça acrescentam outros elementos importante para a compreensão desse conjunto complexo de representações. As versões dos entrevistados sobre o que poderia ser considerado maior exemplo de injustiça social apontam fatores oriundos de diversas instâncias da vida coletiva.

Os exemplos de injustiça social referem-se à centralização de poder, à discriminação social, ao maltrato de crianças e mulheres. Exemplos de injustiça enfocam também o privilégio de "políticos que viajam demais, que tem salários e mordomias". É também considerada injusta a existência de uma disparidade de classe: "um pai de família ganhar um salário mínimo enquanto um deputado ganha muito".

Outra constelação de percepções exemplifica as carências sociais com base em vários aspectos: falta de saúde, falta de direito, falta de educação, falta de alimentação, falta de casa própria, falta de emprego, indigência, miséria, discriminação com os pobres, falta de respeito pelo ser humano. A essa frequência de respostas segue-se a desigualdade econômica e salarial que sintetiza as distâncias sociais em diversos níveis: “A injustiça social está na discriminação entre pobres e ricos".

A ideia de discriminação social estende-se também a relações de gênero, recobrindo aspectos que incidem sobre direitos sociais de homens e mulheres. Para 52\% dos entrevistados, a igualdade ainda não existe, por conta da existência de preconceitos. No entanto, todos os depoimentos afirmam que homens e mulheres deveriam ter os mesmos direitos. Os discursos fundamentam-se também no argumento da igualdade entre os sexos, exemplificada na capacidade feminina de trabalho e administração política. É importante ressaltar 
que a presença de mulheres na direção de associações de moradores é equivalente à de homens, aparecendo na própria amostra da pesquisa que incorporou 55\% de mulheres representantes de associações.

As respostas referentes à indagação sobre o que é considerado mais importante para se dizer que um país é democrático condizem com os exemplos já apontados de injustiça social e 61,75 das respostas afirmam que a existência de tratamento igual para todos é condição mais importante para se dizer que um país é democrático. Outros itens tratados no questionário referentes aos critérios da representatividade política, tais como a existência de vários partidos ou a participação em sindicatos e associações foram praticamente negligenciados, atingindo os percentuais de $3 \%$ e $6 \%$.

Os dados obtidos a partir dessa informação condizem perfeitamente com as informações recolhidas por Dagnino (1994) em pesquisa sobre cultura democrática e cidadania realizada em 1993, na cidade de Campinas, em São Paulo. A mesma pergunta que serviu de inspiração ao roteiro da enquete realizada em Fortaleza teve como resposta a afirmação de que o tratamento igualitário para homens, mulheres, ricos e pobres seria o requisito inicial para a existência de um país democrático.

Esses resultados apontam para o fato de que o autoritarismo e a existência de hierarquias sociais foram mais percebidos na avaliação conceitual da sociedade democrática do que as desigualdades econômicas. No entanto, a partir de um outro raciocínio é possível observar um sentido de equivalência entre injustiça, política e desigualdade que fundamenta a própria noção de democracia. Seguramente ela não é vista como estando restrita ao plano das instituições, mas concebida no âmbito das divisões que marcam o espaço social.

A busca de uma espécie de "economia moral", segundo a acepção de E. P. Thompson (1979), inspira essa discussão se for 
possível tomar esse termo em sua complexidade ou diversidade, verificando como as concepções sobre a política articulam-se a critérios normativos ou a "visões de mundo".

As reflexões partem de pressupostos de que vivemos em um mundo marcado por situações de diferenciações e hierarquias propulsoras de discursos que se fazem acompanhar por sentimentos, permanentemente construídos à base de experiências pessoais apreendidas na observação do mundo cotidiano. ${ }^{7}$

É a existência de uma "injustiça social", atuando como espécie de cena primordial da política que explica e existência de diferenças ou desigualdades. Nesse contexto, observa-se o aparecimento de uma concepção nativa de injustiça não referida imediatamente a um campo jurídico, mas baseada em princípios normativos de distribuição de bens sociais e econômicos.

Uma outra perspectiva de avaliação sobre os princípios morais que regulam os comportamentos tem na esfera individual e hereditária sua explicação mais contundente. Nesse sentido, 53\% dos informantes apontam a existência de pessoas que "já nascem com tendência para infringir a lei”. Observa-se, portanto, uma ordem normativa de dupla face que considera as diferenças como estando induzidas pela "injustiça social", concebendo também os crimes como circunscritos à "natureza humana".

Essas percepções aparentemente contraditórias revelam a existência de duas matrizes discursivas. Uma é oriunda de um senso comum que omite as origens históricas das desigualdades e a outra, construída por supostos normativos vindos de um pensamento crítico, baseado em valores partidários ou princípios difundidos pela Teologia da Libertação.

Dentre as situações merecedoras de punição judicial destacaram-se, em primeiro plano, o assassinato seguido de roubo. 
Este último poderia ser circunstancialmente justificável perante a evidência de necessidades. "Já pensou, um pai de família procurar um emprego, não conseguir e os filhos com fome? Ele perde a cabeça e rouba mesmo". A justificativa para esse tipo de infração leva a pensar que a injustiça social é concebida como expressão máxima das desigualdades sociais.

A necessidade de punição judicial não justifica a pena de morte que tem $67 \%$ de opiniões desfavoráveis. São opiniões justificadas pelo temor de que a justiça não aja com isenção. Registros sobre esse aspecto merecem ser mencionados: "Só iam morrer os pobres, os miseráveis e os negros"; "Quem ia pagar era só os coitados, que não têm defesa, os grandes não"; "Quem tá no poder é quem manda. No nosso país, só quem iria morrer era ladrão de galinha”.

Outras respostas favoráveis à pena de morte foram justificadas como modo de conter a violência: "Se existir a pena de morte no país, se morrer alguns a situação vai melhorar, principalmente nos casos de estupro"; "Sendo bem dirigida e bem investigada, se houvesse pena de morte, 90\% dos crimes diminuiria". Uma decodificação dessas opiniões aponta, no entanto, que a demanda por uma atuação mais forte das instituições está subjacente ao raciocínio, considerando que os informantes também argumentaram que se elas funcionassem de forma eficiente não haveria a necessidade da punição extrema.

A estreita vinculação entre a injustiça social e desigualdade evidencia um modo de imaginar a realidade social vista a partir de clivagens e privilégios que se reproduzem nas instituições. Assim como a política aparece dividida entre o bairro e as instâncias oficiais de representação, os princípios de moral e justiça parecem expressar uma dupla cidadania: a dos que detém a posse de bens materiais e simbólicos e os excluídos desses benefícios. Destaca-se, nessas concepções, uma profunda descrença nas instituições, vistas como espaço de solidificação de privilégios sociais. 
Nesse momento valeria a pena mencionar a construção de um espaço dualizado que informa as representações sobre os mecanismos de inclusão e exclusão social. Todas essas questões repõem a temática da exclusão, não a partir dos critérios nomeados "objetivos", mas com base em dimensões normativas que incidem sobre o plano das representações sociais. Isso implica verificar como a idéia de pertencimento social é pensada e sentida, constituindose com base em um lugar construído também simbolicamente. Os moradores, pondo-se na condição de desprivilegiados, seriam, assim, a expressão concreta de uma matriz simbólica acionadora de uma correspondência entre estrutura social e estrutura mental, conforme as reflexões de Bourdieu (1996) a respeito dos esquemas mentais como incorporação de estruturas objetivas.

Nessa direção poderiam ser destacados alguns registros que presidem o conjunto das representações dos informantes enunciadas ao longo do artigo:

1) percepção do Espaço social como estando fortemente marcado por situações de exclusão.

2) percepção da política e do poder como distantes e indutores de privilégios e de sentimentos de exclusão

3) percepção da moral associada a uma condição de classe.

Os entrevistados têm uma clara noção da existência de um espaço social diferenciado, em torno do qual se erguem as possibilidades e limites de mudança. Sobre esse espaço social elaboram uma visão crítica que convive com as ideias provenientes de um senso comum instituído: as desigualdades, embora injustas, constituem partes inerentes à sociedade, vigentes "desde que o mundo é mundo". Destaca-se, nesse sentido, uma visão de praticidade ou de resignação respeitosa tal como observou Thompson (1995) a propósito da produção e consumo de bens que cercam o mundo dos 
dominados. Um mundo percebido, sobretudo, a partir da existência de uma distribuição desigual de benefícios articulados a um exercício de poderes considerados passíveis de controle. ${ }^{8}$

Essa concepção de mundo não rompe com a possibilidade de que os informantes possam mobilizar ações de contestação no interior do campo político. É importante lembrar que os moradores eram indivíduos que tiveram uma "socialização política" efetivada através de atividades desenvolvidas no bairro, sendo participantes em diferentes experiência associativas. Sete dos entrevistados foram, inclusive, candidatos a vereador nos pleitos de 1992 e 1996. Em anos mais recentes, alguns dos entrevistados tornaram-se funcionários de ONGs ou foram incorporados a órgãos do governo, sob a direção do PT.

Existe, portanto, nas representações dos entrevistados, um sentido de injustiça que se faz acompanhar de descrença na política. Talvez aqui seja interessante pensar em um jogo de sentidos que inclui as dimensões críticas e naturalizadas do mundo social: a "injustiça" como fruto de um espaço habitualmente indutor de desigualdades.

A descrença nas instituições não pode ser pensada como fruto direto de uma "consciência coletiva" herdada do autoritarismo. Heranças culturais sedimentadas afirmam a existência longínqua de um poder coercitivo, originado da própria história dos subsistemas econômicos e administrativos. A pesquisa da equipe do Cedec, coordenada por Moisés em 1991, a respeito da existência de uma "cultura política" democrática ressalta os efeitos contraditórios movidos por desencontros entre instituições, baseadas em regras e práticas democráticas e descrença nos procedimentos institucionais. Esse fato permite pensar que, para alguns segmentos sociais, o desejo de ordenamento e inclusão não necessariamente passa pela crença de que ele poderia ser gerido pelos espaços institucionalizados vigentes. Assim, compreende-se porque a percepção da existência de uma 
dualidade no espaço de distribuição dos bens materiais incide em outros antagonismos atribuídos ao campo da política (a política do bairro e a política dos políticos) e no campo jurídico (a justiça dos pobres e a justiça dos ricos). Não é de estranhar, portanto, que os valores de identificação que presidem a escolha do considerado bom político apareçam de modo contundente. O "mundo dos pobres" e o "mundo dos ricos" integram a terminologia que dá sentido metafórico a um conjunto de opiniões de segmentos sociais que se reconhecem como estando do lado perdedor.

Menos que qualificar essa dimensão das representações como exemplo de um pensamento conservador, é importante pensar na existência de esquemas mentais classificatórios que alimentam a existência de desigualdades sociais. A precariedade vista assim como exclusão simbólica aponta para a perspectiva de uma concepção sobre as desigualdades sociais não restrita à posse de bens materiais, ressaltando-se a pobreza de direitos, sentimentos de injustiça ou sentimento de não pertencimento (Telles, 1993).

Verificar como as temáticas se articulam, como formam recorrências, revelando sentidos e experiências constituiu a tentativa final de organização dos dados que buscaram tratar as representações em seu contexto de referência, evitando o risco de tomar o conjunto de opiniões como expressivas de uma "cultura política" em torno da qual poderiam ser emprestados adjetivos tais como conservadora ou democrática.

As representações exigem, portanto, do analista-pesquisador, uma interpretação das informações a serem submetidas a referentes teóricos. Supõem a análise de códigos de percepção e mapas de navegação dos grupos e segmentos contemplados na investigação. Explicitadas por meio de categorias nativas, as representações servem para decifrar situações, fornecendo bússolas de entendimento da vida social. 
Algumas breves e não necessariamente inovadoras reflexões sobre as potencialidades e cuidados no uso do conceito de representações, a serem também submetidas a novas investigações, servem de arremate às questões pontuadas neste artigo.

\section{Potencialidades e dilemas na utilização do conceito}

O conceito de representações sociais foi eficaz na tentativa de aplicação a objetos com recortes precisos, em espaços macro ou microssociais. Representações sobre doenças em determinados segmentos, sobre atitudes diante de fatos, crenças religiosas, ou comportamentos característicos de agrupamentos sociais povoaram uma ampla literatura no espaço das ciências humanas, englobando Psicologia, Sociologia e Antropologia. No campo dos estudos sobre a violência, as investigações apontaram recortes interessantes à análise, servindo para validar e redefinir alguns postulados teóricos. ${ }^{9}$ Os meios de comunicação de massa também constituíram um espaço vasto de pesquisas voltadas, sobretudo, para as formas de recepção variadas entre grupos e categorias sociais.

Em substituição a categorizações amplas, identificadas anteriormente na Sociologia como visões de mundo associadas às classes sociais ou ideologias, o conceito de representações apontou a eficácia de lidar, de forma mais operacional e concreta, com discursos pontuais, trabalhando concepções plurais fora de um estatuto normativo.

A teoria das representações herdada das concepções de Durkheim também se modificou na reflexão contemporânea do tema, apontando possibilidades plurais de expressão e reconhecimento das diversidades, não redutíveis a um coletivo determinante. Enquanto a Psicologia teve que fazer um desdobramento em direção ao "social", a Sociologia reafirmou a força do coletivo cultural, incluindo, também, as experiências individuais ou grupais como parte das 
representações. As novas pesquisas incorporaram a pluralidade e a diversidade de percepções e vivências que pontuam a sociedade contemporânea, articuladas a processos cognitivos pelos quais os sujeitos dão sentido ao mundo. ${ }^{10}$

O registro de percepções, expressivo de pensamentos e situações da vida social tornou operacional as pesquisas, evocando muitas possibilidades de aplicação a moradores e trabalhadores de várias categorias. As investigações, por diferentes caminhos, apontavam uma heterogeneidade de valores típicos de uma sociedade em processos permanentes de mudança, tal como foi realçado por Moscovicci (1989), reportando-se ao papel difusor e multiplicador das representações, promovido pelos meios de comunicação de massa.

Foi justamente a percepção da variabilidade de representações entre grupos e segmentos que permitiu ao conceito uma dosagem de operacionalidade capaz de apontar o efeito de situações sobre a formação de determinados modos de pensar e interpretar a realidade social.

A abordagem das representações também corroborou para o registro de dimensões subjetivas de atores sociais, supondo que eles não são passivos na recepção de conteúdos. As representações, nesse sentido, deram suporte a teorias da recepção concebidas no realce da capacidade de os indivíduos reelaborarem mensagens e discursos. Ressaltou-se, nesse sentido, o lado criativo e dinâmico das representações sociais, capaz de articular sistemas culturais e processos cognitivos.

O risco de engessamento do conceito de representações ocorre quando elas passam a significar a expressão de visões estruturadas e fixas, transformando o circunstancial em permanente. Afirmações baseadas em enquetes que visam apresentar o "pensamento dos jovens", o "pensamento das mulheres", ou as "visões de mundo dos pobres" constituem exemplos da necessidade do uso cuidadoso do 
conceito. Trata-se de relativizar a opinião conjunta de informantes, proveniente, em muitas situações, de universos culturais heterogêneos, não necessariamente unificados por meio de enquetes.

Mais do que circunstanciar as representações, sinalizando o lugar do qual elas emergem, trata-se de retirá-las do estatuto de um cardápio de opiniões, pensando-as como categorias nativas que produzem mapas de navegação social. Corre-se o risco de cristalizar concepções que podem mudar segundo as circunstâncias, porque estão ligadas a concepções variadas da vida social, domínio no qual as opiniões dão lugar a múltiplas interpretações. É o caso das opiniões sobre a pena de morte que, antes de apontarem um estado definitivo de percepção, podem significar uma demanda por justiça baseada nos direitos e deveres de cidadania. Situar o contexto das representações, tentando compreender seus mecanismos de construção, pode ser um caminho válido para analisar valores e sentidos elaborados por segmentos sociais determinados.

As representações na política não estão separadas de outras representações existentes na vida social, conforme foi observado na pesquisa. Ao contrário, evocam um sentido de "totalidade" à medida que se associam à visão de posições sociais, desigualdades e supostos morais. Por outro lado, em se tratando de versões sobre a política não deixa de ser relevante a força dos meios de comunicação no sentido de induzir a produção de um certo "senso comum".

A pesquisa que deu subsídios a este artigo aponta algumas questões interessantes que se impuseram no decurso da análise e na coleta das informações. Nesse caso, a operacionalidade do conceito de representações como ferramenta metodológica amparou-se na reconstituição do universo cultural dos informantes, a partir do qual foram lidos os discursos sobre a moral e a política.

Ficou evidente no circuito das representações a existência de várias matrizes discursivas que serviam de suporte à construção 
de versões sobre a moral, a política e as desigualdades sociais. Estas apontaram valores adquiridos ao longo de uma experiência de sociabilidade nos bairros pesquisados, agregando práticas associativas, crenças e uma percepção de inserção no espaço societário que poderia ser nomeada "sentimento de exclusão". Nessa perspectiva, discursos aparentemente contraditórios, que poderiam ser interpretados como manifestação de desencanto ou descrença na política, traduziam, na realidade, versões diferenciadas e polarizadas sobre as práticas de participação dos atores no âmbito institucional.

Foi o conhecimento do contexto social de produção das representações que permitiu uma interpretação da palavra "política" utilizada para designar vários comportamentos, inclusive as práticas associativas das entidades de bairro consideradas, a priori, como "não políticas".

A "política dos bairros", os políticos e a "outra política" com suas adjetivações foram utilizadas como categorias nativas que exigiram uma análise das representações com base em um espaço cultural de referência mais amplo. Circunstanciar as representações, verificando usos e empregos utilizados em situações variadas, supôs a necessidade de agregar à enquete outras técnicas de pesquisa de modo a pensar no circuito maleável das palavras que, não sendo “apenas palavras, também constituíam e difundiam fatos" (Latour, 1983).

Na pesquisa entre os moradores da periferia urbana deFortaleza, o que parecia designar uma "visão realista" das impossibilidades de superar hierarquias e ultrapassar as barreiras de classe associava-se a valores libertários, oriundos das concepções sobre direitos sociais que integraram a história dos movimentos sociais urbanos desde a década de 1970 .

Assim, buscar matrizes discursivas como antecedentes de "opiniões", permite lidar com a polissemia das palavras e as 
"contradições" que elas sinalizam, evitando a esterilidade descritiva da maioria das enquetes, já criticadas por Moscovicci em vários de seus trabalhos. Do mesmo modo, a decodificação das representações sobre a política, antes de apontar simplesmente um desencanto, ou aversão às instituições, dizem muito das formas de ressentimento que os moradores vivenciam em relação a um campo de atividades percebido como distante e muitas vezes inacessível.

A análise das representações circunstanciadas da pesquisa revelou a fecundidade do conceito e os limites ou cuidados necessários à manutenção de seu valor heurístico criativo.

\section{Notas}

1 Uma exposição sobre o percurso teórico do conceito de representações encontra-se em Farr (1995).

2 Uma síntese do material de pesquisa encontra-se em Barreira (2001).

3 Uma explicação mais detalhada de alguns dos princípios que orientaram a pesquisa encontra-se em Palmeira et al. (1998).

4 Para uma reflexão sobre o conceito de cultura política e seus possíveis diálogos com a Antropologia, ver Kuschnir (2007).

5 Para uma discussão sobre o caráter itinerante da política em bairros da periferia urbana, sobretudo em períodos eleitorais, ver Barreira (2006).

6 Uma reflexão sobre o estatuto das candidaturas populares encontra-se sistematizada em Barreira e Firmo (1994).

7 Claudette Lafaye (1990) discute, por exemplo, as formas de elaboração de justiça no universo do trabalho baseando-se em um quadro de análise elaborado por Luc Boltanski a respeito dos registros de justiça mobilizados por pessoas comuns em situações de tensão social.

8 Em uma perspectiva mais voltada para a análise de laços sociais e representações ligadas à nocão de respeito, Dominique Vidal (1998), 
em estudo etnográfico realizado em um bairro de Recife, capital do Estado do Pernambuco, considera as dificuldades do estabelecimento de uma noção de democracia por conta de valores ambivalentes originados tanto de uma prática hierárquica, que garante aos pobres um lugar social, como de uma visão de sociedade baseada em direitos iguais, que supõe a existência da similitude e dá a cada um a possibilidade de atingir posições socialmente valorizadas.

9 Porto (2006) propõe-se a avançar no tema da reflexão sobre a violência através da análise das representações sociais, verificando o caráter imprescindível destas na percepção dos sentidos, dos valores e das crenças que estruturam e presidem a vida social.

10 Ver, a esse respeito, o artigo de Jovchelovitch (1994).

Representations on politics as found among popular leadership: limits and potentialities of a conceptual tool

\begin{abstract}
The idea of considering representations according to their dynamic configuration, as they are perceived within living experiences and political actions, inspired the main concepts explored by the article. Based on research that investigated residents of the suburbs of the city of Fortaleza, capital of Ceará state, with the help of the technique associated with ethnographic experience, the article evaluates representations within a context of cultural meanings set as examples to native categories. The investigation was directed towards delineating potentialities and limits of representations seen as a conceptual tool when it evaluates the way informants assess issues related to politics and morals associated with themes of justice and social inadequacies.
\end{abstract}

Keywords: representations; politics; moral; leadership.

\title{
Referências bibliográficas
}

AVRITZER, Leonardo. Cultura política, atores sociais e democratização. Revista Brasileira de Ciências Sociais, São Paulo, n. 28, 1995. 
BARREIRA, Irlys. Política moral e cidadania no contexto de atores sociais urbanos. Revista de Ciências Sociais da UFC, v. 32, n. 1/ 2, p. 4152, 2001.

BARREIRA, Irlys; FIRMO, B. I. A. A representação como espelho: universo cultural e político das candidaturas populares. Revista Brasileira de Ciências Sociais, n. 26, p. 149-161, 1994.

. A política de perto. Novos Estudos, Cebrap. São Paulo, 2006.

BOURDIEU, Pierre. Razões práticas: sobre a teoria da ação. São Paulo: Papirus, 1996.

. Efeitos de lugar. In: BOURDIEU, Pierre (Coord.). A Miséria do mundo. Petrópolis: Vozes, 1997.

CALDEIRA, Tereza. A política dos outros. São Paulo: Brasiliense, 1984.

CHAMPAGNE, Patrick et al. Iniciação à prática sociológica. Petrópolis: Vozes, 1998.

COSTA, Sérgio. Movimentos sociais, democratização e a construção de esferas públicas locais. Revista Brasileira de Ciências Sociais, São Paulo, n 25, 1997.

DAGNINO, Eveline. Os movimentos sociais e a emergência de uma nova noção de cidadania. In: DAGNINO E. (Org.). Anos 90 política e sociedade no Brasil. São Paulo: Brasiliense, 1994.

FARR, Robert. O conceito de representações sociais: a teoria e sua história. In: JOVCHELOVITCH, Sandra; GUARESCHI, Pedrinho. Textos em representações sociais. Petrópolis: Vozes, 1994.

JODELET, Denise. Les répresentations sociales. Paris: Presses Universitaires de Francen (PUF), 1994.

JOVCHELOVITCH, Sandra. Vivendo a vida com os outros: intersubjetividade, espaço público e representações sociais. In: JOVCHELOVITCH, Sandra; GUARESCHI Pedrinho.Textos em representações sociais, Petrópolis: Vozes, 1994.

KUSCHNIR, Karina. Antropologia da Política. Rio de Janeiro: Zahar, 2007. 
LAFAYE, Claudette. Situations tendues et sens ordinaires de la justice au sein d'une administration municipale. Revue Française de Sociologie, n. 31, 1990.

LATOUR, B. Le grand partage? Revue de Synthèse. Paris, n. 5, 1983.

MAgAlHÃeS, Nara. O Povo sabe votar, uma visão antropológica. Petrópolis: Vozes, 1998.

MOISÉS, José Álvaro. Democratização e cultura política de massas no Brasil. Lua Nova, Revista de Cultura e Política, São Paulo, n 26, 1992.

MOSCOVICI, Serge. Des répresentations collectives aux représentations socials. In: JODELET, Denise. Les répresentations sociales, Paris : Presses Universitaires de France (PUF), 1994.

PALMEIRA, Moacir et al. Uma antropologia da política: rituais, representações e violência. Cadernos do NUAP, Rio de Janeiro, n. 1, 1998 .

PALMEIRA, Moacir. Política, facções e voto. In: PALMEIRA, Moacir; GOLDMAN, Márcio. Antropologia, voto e representação política. Rio de Janeiro: Contracapa, 1996.

PORTO, Stela Maria Grossi. Crenças, valores e representações sociais da violência. Sociologias, Porto Alegre, n. 16, jul./dez, 2006.

TELLES, Vera da Silva. Pobreza e cidadania: dilemas do Brasil contemporâneo. Caderno CRH, Salvador, n. 19, 1993.

THOMPSON, Edward P. Tradicion, revuelta y consciência de clase: estudios sobre la crises de la sociedad preindustrial. Barcelona: Crítica, 1979.

VIDAL, Dominique. Le respect: catégorie du social, catégorie du politique dans une favela de Recife. Paris, 2000. [não publicado].

ZALUAR, Alba. Exclusão e políticas públicas: dilemas teóricos e alternativas políticas. Revista Brasileira de Ciências Sociais, São Paulo, v.12, n. 35, p. 29-47, fev. 1997. 